OMEGA, Vol. 55(3) 237-253, 2007

\title{
TELECOMMUNICATION AND SUICIDE PREVENTION: HOPES AND CHALLENGES FOR THE NEW CENTURY
}

\author{
KAROLINA E. KRYSINSKA
}

DIEGO DE LEO

Griffith University, Brisbane, Australia

\begin{abstract}
Development of information technology has created new opportunities and challenges in suicide prevention, research, and clinical practice. This article presents an overview of the wide range of telecommunication-based suicide prevention approaches. Interventions using the Internet, telephone, and videoconferencing are discussed, including crisis intervention, referral, and support, suicide risk assessment, psychotherapy for individuals at risk, and online-based suicide prevention training and education. Research regarding effectiveness of telecommunication-based suicide prevention in various demographic and clinical populations is reviewed, as well as concerns regarding this type of intervention. Future areas of research and development in the use of telecommunication media in prevention of suicide are discussed.
\end{abstract}

\section{INTRODUCTION}

Prevention of suicide is a challenging task. Although a wide variety of initiatives and approaches have been developed and introduced in many countries worldwide, suicidology is still searching for evidence-based, effective, and sustainable ways of preventing suicidal behaviors. Reviews of available evidence indicate that some approaches yield promising results, although methodological shortcomings (including small sample size, follow-up periods of short duration, and recruitment 
biases) require caution in interpreting their results. This article presents an overview of the wide range of telecommunication-based suicide prevention approaches and is based upon literature published in English over the period 1966-April 2006 identified via the PubMed and ProQuest databases.

Development of information technology and opening of new communication channels have created new opportunities in suicide prevention, research, and clinical practice. Telecommunication technologies, including telephone, videoconferencing, and the Internet, have been used to provide support to individuals in crisis, to supplement psychotherapy, and to increase treatment compliance and motivation among individuals with a history of suicidal behavior. They have also been utilized for screening and assessment of suicide risk, and to provide education and training to mental health professionals and the general public. Table 1 gives a brief overview of the range of suicide prevention approaches based upon the use of telecommunication technology.

\section{TELEPHONE SERVICES AND SUICIDE PREVENTION}

Telephone services are the traditional telecommunication medium for crisis intervention and suicide prevention (Varah, 2001). Telephone has been used to provide support to individuals in crisis (King \& Frost, 2005; Lester, 2005; Mishara \& Daigle, 2001), to deliver brief psychotherapy (Rhee, Merbaum, Strube, \& Self, 2005) and to provide information and support to relatives and friends of suicidal individuals (Mishara, Houle, \& Lavoie, 2005). Telephone services have also been utilized in an attempt to improve treatment compliance and outcome in patients with a history of suicidal behavior (Cedereke, Monti, \& Ojehagen, 2002; De Leo \& Heller, in press; Evans, Morgan, \& Hayward, 2000; Evans, Morgan, Hayward, \& Gunnell, 1999) and to assist the elderly at risk of suicide (De Leo, Carollo, \& Dello Buono, 1995; De Leo, Dello Buono, \& Dwyer, 2002).

Many hotlines worldwide have been operational for decades and data shows that both individuals in crisis and third parties concerned about somebody else's well-being frequently use such services (Bale, 2001; Barber, Blackman, Talbot, \& Saebel, 2004; Mishara et al., 2005). However, to date there is paucity of studies and research data supporting the effectiveness of telephone services in suicide prevention. The major hindrances to collecting data in this area are the very factors seen as the greatest advantages of phone crisis intervention: anonymity and confidentiality of services. Anecdotal evidence, as well as studies looking at clients' and counselors' satisfaction with provided interventions, repeated use of services, and referral outcomes, show positive results (King, Nurcombe, Bickman, Hides, \& Reid, 2004; Mishara, 2005). However, ecological and time-series studies yield conflicting results or indicate that suicide hotlines may help to reduce suicide rates in particular sub-populations, e.g., young white females (Dew, Bromet, Brent, \& Greenhouse, 1987; Gould \& Kramer, 2001; Lester, 1997; Miller, Coombs, Leeper, \& Barton, 1984). 
Table 1. Use of Telecommunication Technology in Suicide Prevention: Approach Examples

\begin{tabular}{|c|c|c|}
\hline & $\begin{array}{l}\text { Telephone (including } \\
\text { videoconferencing) }\end{array}$ & Internet \\
\hline Prevention & $\begin{array}{l}\text { - Support services for high } \\
\text { risk populations (e.g., Tele- } \\
\text { Help/Tele-Check service for } \\
\text { the elderly: De Leo et al., } \\
\text { 1995; 2002) }\end{array}$ & $\begin{array}{l}\text { - Support and information } \\
\text { Websites for individuals at } \\
\text { risk (e.g., Reach Out!: } \\
\text { Commonwealth Department } \\
\text { of Health and Aged Care, } \\
\text { 2000) }\end{array}$ \\
\hline \multirow[t]{6}{*}{ Intervention } & \multirow{2}{*}{$\begin{array}{l}\text { - Crisis intervention and } \\
\text { referral for individuals at risk } \\
\text { of suicide (e.g., the } \\
\text { Samaritans: Bale, 2001) }\end{array}$} & $\begin{array}{l}\text { - E-mail-based crisis interven- } \\
\text { tion (e.g., jo@samaritans.org: } \\
\text { Howlett \& Langdon, 2004) }\end{array}$ \\
\hline & & \multirow[b]{2}{*}{$\begin{array}{l}\text { - Referral and support services } \\
\text { via an online discussion group } \\
\text { and contact with trained } \\
\text { volunteers for individuals in } \\
\text { suicidal crisis (e.g., SAHAR: } \\
\text { Barak, 2007) }\end{array}$} \\
\hline & $\begin{array}{l}\text { - Support and referral infor- } \\
\text { mation for individuals } \\
\text { concerned about a suicidal } \\
\text { relative or friend (Mishara } \\
\text { et al., 2005) }\end{array}$ & \\
\hline & \multirow{2}{*}{$\begin{array}{l}\text { - Brief psychotherapy for } \\
\text { low-risk suicidal clients } \\
\text { (Rhee et al., 2005) }\end{array}$} & $\begin{array}{l}\text { - Self-help chat rooms (Murphy } \\
\text { \& Mitchell, 1998) }\end{array}$ \\
\hline & & \multirow{2}{*}{$\begin{array}{l}\text {-Web-based suicide risk } \\
\text { assessment (Ellen, 2002) }\end{array}$} \\
\hline & $\begin{array}{l}\text { - Suicide risk assessment via } \\
\text { teleconferencing (Jong, } \\
\text { 2004) }\end{array}$ & \\
\hline Postvention & $\begin{array}{l}\text { - Follow-up interventions } \\
\text { aimed at improving } \\
\text { treatment compliance and } \\
\text { effectiveness of psycho- } \\
\text { therapy with suicide } \\
\text { attempters (e.g., Green } \\
\text { Card program: Evans et al., } \\
\text { 1999, 2000) }\end{array}$ & $\begin{array}{l}\text {-Website-based information, } \\
\text { referral, support, and mailing } \\
\text { lists for suicide survivors } \\
\text { (Stoney, 1998) }\end{array}$ \\
\hline $\begin{array}{l}\text { Education } \\
\text { and Training }\end{array}$ & & $\begin{array}{l}\text {-Website-based suicide } \\
\text { prevention skills training for } \\
\text { general population and } \\
\text { mental health professionals } \\
\text { (e.g., electronic Suicide } \\
\text { Prevention Skills Training: } \\
\text { Hawgood et al., 2006; } \\
\text { QPR Online Courses: } \\
\text { Quinnett, 2004) }\end{array}$ \\
\hline
\end{tabular}


Besides short-term crisis intervention, telephone has been used to provide psychotherapy to hotline callers as an alternative to an outside referral. Rhee et al. (2005) conducted an effectiveness study of a brief telephone intervention delivered to suicide hotline callers and concluded that it is "a viable service to offer prospective clients particularly when face-to-face options are ether unavailable or inconvenient" (p. 326). However, these results cannot be generalized to individuals at medium and high levels of suicide risk, as due to ethical and legal considerations only individuals at no or low suicide risk were deemed eligible to participate in the study. Mishara et al. (2005) reported using another innovative approach to telephone-based suicide prevention: a project aimed to provide support and information to hotline callers concerned about a suicidal male, either a relative or a friend. The study results indicated that programs designed to help third-party callers might be beneficial to both the callers and men at risk of suicide, a high-risk population infrequently contacting crisis services or other mental health professionals.

Telephone-based support has also been proposed to provide crisis consultations or increase treatment compliance for individuals with a history of suicidal behavior. In studies by Evans et al. $(1999,2000)$ patients discharged from hospital after a suicide attempt were offered "green cards" encouraging them to use a 24-hour phone consultation service with an on-call psychiatrist, provided they have not engaged in self-harming behavior prior to the contact. Study results showed that the crisis cards did not increase compliance with outpatient psychiatric treatment, with only a minority of study participants using the card. Unlike a previous study using a similar system (Morgan, Jones, \& Owen, 1993), and a trial analyzing the effects of a series of short letters expressing concern with the patient's well-being sent to individuals who refused ongoing treatment (Motto, 1976; Motto \& Bostrom, 2001), no reduction in repetition of self-harming behavior was found.

Cedereke et al. (2002) conducted a study analyzing the impact of telephone contact maintained between health services and individuals who have attempted suicide on treatment compliance and repetition of suicidal behavior. Results showed that there were no differences between individuals in the phone intervention group and the treatment-as-usual group concerning repetition events, suicidal ideation scores, and treatment attendance.

First studies using SMS technology to improve outpatient attendance in primary care yielded promising results (Downer, Meara, \& Da Costa, 2005); possibly, they could be replicated in follow-up interventions for patients with a history of suicidal behaviour (Hatcher \& Owens, 2005).

In an attempt to overcome the elderly people's unwillingness to use phonebased services, a pioneering Tele-Help/Tele-Check program was established in the Veneto region of Italy (De Leo et al., 1995). Tele-Help service is a portable alarm system providing rapid intervention in medical and psychological emergencies, while Tele-Check involves calls from operators to clients at least twice a 
week. De Leo et al. (2002) analyzed the impact of such services on suicidal behavior in individuals aged 65 years and over, and reported that even 10 years after the introduction of the service, a statistically significant lower than expected number of suicidal deaths was observed among service users compared to the general population. Tele-Check proved to be the most influential type of support for the 20,000 elderly users of this type of service.

The same principle of active outreach on the basis of at least two phone calls per week (from Lifeline operators) was recently applied in the context of a controlled trial on the post-discharge phase of patients admitted to a psychiatric ward following a suicide attempt (De Leo \& Heller, in press).

\section{SUICIDE RISK ASSESSMENT VIA VIDEOCONFERENCING}

Jong (2004) reported on a pilot tele-psychiatry project in a rural community in Northern Labrador, Canada. As a part of the project, individuals in a remote location referred for suicide risk assessment were linked via videoconference with a psychiatrist, a local nurse and/or counselors participating in the assessment. The service was effective both in terms of costs involved and clinical outcomes, and patients and mental health providers reported high levels of satisfaction with the service.

\section{WEB-BASED SUICIDE PREVENTION}

Many clinicians and researchers have raised serious concerns regarding negative impact of the Internet on suicidal ideation and behavior of at-risk individuals, especially adolescents and young adults. Most concerns are related to availability of online suicide manuals and detailed descriptions of lethal methods (Mehlum, 2000, 2001; Thompson, 2001), as well as the risk of virtual "Werther effect" or "copycat cybersuicides" (Baume, Cantor, \& Rolfe, 1997; Becker \& Schmidt, 2004). Also, there have been reports of suicide pacts initiated over the Internet (Rajagopal, 2004).

The Internet has been widely used also as a tool for suicide prevention. Online suicide risk screening programs have been developed and implemented (Ellen, 2002), and reports of interventions in cases of individuals who planned or attempted suicide, identified using Web-based facilities, have been published (e.g., Ball, 2000; Janson et al., 2001). E-mail communication has been used for crisis intervention (Bale, 2001; Howlett \& Langdon, 2004; Wilson \& Lester, 1998), and Websites and mailing lists have been developed to assist clinical services, and raise the awareness on suicide prevention issues among the general public and health professionals (Mehlum, 2000; Penn et al., 2005; Stone, Barber, \& Potter, 2005; Stoney, 1998). For example, in Israel, the SAHAR Website ("Support and Listening on the Net") was launched to provide referral services and 
emotional support to individuals in suicidal crisis via online discussion group and contact with trained volunteers (Barak, 2007). Although anonymity and confidentiality limit the process of data collection, the SAHAR Website reports approximately 350 visitors per day, with volunteers contacting approximately 500 suicidal individuals a month, corresponding to approximately $50 \%$ of all contacts.

Although befriending by e-mail is based on the same guiding principles of caring as other methods of contact, there are several differences between this method and phone counseling (Griffiths, 2004; Howlett \& Langdon, 2004). Despite its two major disadvantages - i.e., asynchronicity and lack of verbal immediacy-e-mail communication adds an extra degree of anonymity and control, allows for sharing of emotions without having a direct witness, and gives both help seekers and counselors additional time to compose a message (Murphy \& Mitchell, 1998). These factors may be related to a higher degree of interpersonal openness and a more direct expression of hopelessness, despair, and suicidal ideation than that observed over the phone (Bale, 2001; Barak, 2007; Joinson, 1998). In fact, the Samaritans have reported that $53 \%$ of e-mails sent to jo@samaritans.org directly express suicidality as compared to $26 \%$ of phone calls (Howlett \& Langdon, 2004).

The potential of Web-based suicide prevention initiatives as means of raising public awareness and increasing access to services has been recognized by national suicide prevention strategies in several countries, including Australia, New Zealand, the United States, and Norway (Commonwealth Department of Health and Aged Care, 2000; Mehlum, 2001; New Zealand Ministry of Health, 1998; U.S. Department of Health and Human Services, 2001). The National Youth Suicide Prevention Strategy in Australia (1995-1999) led to the development of several Websites, including Reach Out!, an online mental health service providing support and referral information to young people (Commonwealth Department of Health and Aged Care, 2000; Nicholas, Oliver, Lee, \& O'Brien, 2004).

To date there is lack of data concerning the effectiveness of e-mail crisis intervention and Websites providing support and referral to suicidal individuals, although positive feedback from help seekers and volunteers has been reported (Howlett \& Langdon, 2004). Also, there is paucity of research concerning the actual impact of information and services available online on suicidal behavior and ideation. The majority of published material consists of case reports of attempted or completed suicides using methods described online (Beatson, Hosty, \& Smith, 2000; Gallagher, Smith, \& Mellen, 2003; Lee, Chan, \& Yip, 2005; Prior, 2004), descriptions of Web-based interventions and information sources (Baume et al., 1997; Mehlum, 2000, 2001; Sher, 2000), and theoretical analyses of phenomena related to virtual communities and online interpersonal communication (Baume et al., 1997; Becker, Mayer, Nagenborg, El-Faddagh, \& Schmidt, 2004; Becker \& Schmidt, 2004). Although qualitative studies on the dynamics and contents of online communications related to suicide have been 
published (Barak \& Miron, 2005; Birnbaum \& Birnbaum, 2004; Fekete \& Osvath, 2001; Miller \& Gergen, 1998; Sisask, Varnik, \& Wasserman, 2005), more studies are necessary to deepen our knowledge in this area.

\section{ONLINE SUICIDE PREVENTION EDUCATION AND TRAINING}

In addition to specialized e-mail crisis intervention services, a number of Websites has been launched to educate the general public and health professionals about suicide risk factors, warning signs, and referral pathways. For example, ACROSSnet (Australian Creating Rural Online Support Systems) Website aiming to assist rural communities in accessing education, information, and support regarding suicide and its prevention, was developed (Penn et al., 2005). A Web-based suicide prevention training program, the electronic Suicide Prevention Skills Training (e-SPST), was developed at the Australian Institute for Suicide Research and Prevention at Griffith University to increase knowledge and skillsbased competencies of workers in suicide prevention in an effort to increase effective client interventions (Hawgood, Irving, Guo, Gilmour, \& De Leo, 2006).

The QPR Institute, in partnership with Eastern Washington University, offers a blended online version of the Question, Persuade, Refer courses in suicide triage training and risk assessment and management for continuing education and college credit for all healthcare students and working professionals (Quinnett, 2004). Also, the U.S. National Center for Suicide Prevention Training has created online workshops to help service providers, policy makers, and community-based organizations to develop suicide prevention programs and policies (Stone et al., 2005).

To date, there is scarcity of research concerning the effectiveness of educational Websites for the general public and health professionals; however, preliminary results seem to be encouraging. Stone et al. (2005) reported that individuals participating in online workshops developed by the U.S. National Center for Suicide Prevention Training showed consistent improvements in their knowledge of suicide and positively rated their educational experience. Also, the e-SPST program is currently under evaluation in order to assess its impact on client outcomes as measured by worker interventions informed by the training (Hawgood et al., 2006).

\section{CHAT ROOMS AND SELF-HELP FOR INDIVIDUALS AT SUICIDE RISK}

Concerns have been raised regarding online discussion groups and chat rooms focused on the subject of suicide. It has been suggested that despite ambivalence explicitly expressed by many ideators, virtual communities may exert pressure on vulnerable individuals to proceed with a suicide plan, discourage them from 
seeking professional help, share information concerning lethal suicide methods, and recruit members for suicide pacts (Baume et al., 1997; Becker et al., 2004; Mehlum, 2001; Rajagopal, 2004).

However, it has also been hypothesized that online discussion groups may provide support to suicidal individuals by encouraging sharing of thoughts and feelings in a supportive and understanding environment, by strengthening help-seeking attitudes, and providing links to online and offline crisis intervention and mental health services (Becker et al., 2004; Mehlum, 2001). Again, due to serious methodological difficulties, including anonymity of members of online communities, there is scarcity of research in this area. One of the very few published studies looking at therapeutic potentials of online communications is a qualitative study of messages posted on the America Online (AOL) suicide bulletin board and direct interviews with members of the group (Miller \& Gergen, 1998). Results of the study indicated that "within certain domains, a substantial degree of "therapeutic work" can and does spontaneously take place on the Internet" (Miller \& Gergen, 1998; p. 200). The group members positively evaluated the constancy of support, appreciated an opportunity to express themselves, to share useful information, and to engage in mutually helping relationships. They also did not discourage seeking professional help, and considered the online support as a supplement to traditional forms of psychotherapy.

Prasad and Owens (2001) suggested that some of the suicide-related information and self-help facilities available online may be useful for individuals at risk of suicide, although they acknowledged the risk of misinformation and sharing unhelpful or harmful advice. However, Thompson (2001) warned that "although it is true that many regard the Internet information about deliberate self-harm as a valuable service (especially sites devoted to prevention and self-help), a growing body of potentially destructive information that has been acted upon remains, and it would be difficult to recommend that patients contemplating suicide should surf the Internet" (p. 400).

\section{EFFECTIVENESS OF TELECOMMUNICATION-BASED SUICIDE PREVENTION IN SPECIAL POPULATIONS}

Empirical evidence suggests that certain interventions may be more effective in particular age and/or gender groups, or clinical subpopulations. As said, studies examining the impact of hotlines and suicide prevention centers on suicide rates show that such services might be particularly useful for young females (Dew et al., 1987; Miller et al., 1984); however, the elderly and adolescents do not use such services frequently (Adamek \& Kaplan, 1996; Burns \& Patton, 2000; Gould \& Kramer, 2001). Research looking at the effectiveness of Tele-Help/Tele-Check telephone service indicated that the long-term impact of the system was significantly higher among older females than males (De Leo et al., 1995, 2002). Evans et al. $(1999,2000)$ reported that males were more willing to use the 
emergency "green cards" offered to them at discharge from a hospital after a suicide attempt than females, and individuals with a history of repeated suicidal behavior contacted crisis telephone services more often than first-timers.

Some studies concerning gender differences in help seeking produced conflicting data. It is often suggested that females are more willing to use phone crisis intervention services than males (e.g., Miller et al., 1984; Mishara et al., 2005), and males may use e-mail services more frequently than females (Howlett \& Langdon, 2004; Wilson \& Lester, 1998). However, Barber et al. (2004) reported that almost exactly the same number of suicidal females and males call a hotline, while data concerning the use of e-mail services provided by the Samaritans showed that females comprise the majority of help seekers (Howlett \& Langdon, 2004).

Surveys show that adolescents often use the Internet as a source of health information, including topics related to mental health. Due to its availability, anonymity, and interactivity, the Internet represents an attractive tool for young people of both sexes (Borzekowski \& Ricket, 2001; Nicholas et al., 2004). Gould et al. (2002) reported that male and female college students, especially teenagers with impaired functioning and hopelessness feelings, use the Internet to look for help when experiencing suicidal thoughts. Similar to results from other studies (e.g., Ybarra \& Suman, 2006), the authors found that online sources of information and help are used in addition to, not instead of, other formal and informal resources and services.

\section{SUICIDE PREVENTION AND INFORMATION TECHNOLOGY: FURTHER CONCERNS}

The use of telecommunication-based technologies in interventions with suicidal individuals raises several issues, with psychotherapists and other mental health professionals being advised against counseling and treating suicidal patients online (Goss \& Anthony, 2004; Kraus, 2004; Wright, 2004). The major disadvantages of such interventions are based on the limited risk assessment opportunities due to lack of visual clues, client's anonymity, as well as limited access to consultation, referral, emergency care, and hospitalization services (Goss \& Anthony, 2004; Koocher \& Morray, 2000; Maheu, Pulier, Wilhelm, McMenamin, \& Brown-Connolly, 2005).

Maheu et al. (2005), in their discussion of clinical standards and guidelines for mental health professionals using new communication technologies, recommend "full prohibition of e-mail clinical practice in emergencies. (...) When receiving an unexpected e-mail message describing suicidal or homicidal intent, a practitioner may not be able to thoroughly assess the patients. The truth is that a solo professional operating online may be less able to gather crucial information or to act with sufficient speed than someone who can actually go to the emergency scene. Furthermore, a remote professional may trend to overestimate the 
immediate effectiveness oft the therapeutic relationship or may tolerate too much immediate risk in order to preserve the relationship for long-range goals" (pp. 269-270).

Legal solutions targeted at reducing the risk of online suicide contagion and restricting access to Web-based information about lethal means of suicide have been developed in some countries. In 2005, the Australian government introduced laws criminalizing the use the Internet to incite or counsel suicide, including producing, supplying, or possessing materials promoting and providing instructions on a particular suicide method (Minister of Justice and Custom, 2005).

\section{CHALLENGES FOR THE FUTURE}

Burgeoning suicide prevention initiatives and programs based upon telecommunication technologies have not been accompanied by a parallel development of research projects and methodology to evaluate their effectiveness. Only a few controlled randomized trials were conducted to look at the clinical effectiveness of telephone-based interventions (Cedereke et al., 2002; Evans et al., 1999, 2000; Rhee et al., 2005). Besides ecological and time-series correlational studies, and some qualitative research analyzing the immediate effects of hotline interventions, still there is paucity of research concerning the effectiveness of phone-based crisis interventions. The guiding principles of anonymity of callers and confidentiality of services do not allow for randomized controlled follow-up studies and, additionally, create ethical and legal problems related to data collection. In order to overcome the latter, the Silent Monitoring Study of the U.S. National Hopeline Network used the Virtual Private Network to protect callers' confidentiality (Mishara, 2005).

Although correlational studies show an impact of crisis intervention centers on suicide rates, they do not allow for drawing cause-and-effect conclusions (Lester, 1997). Anecdotal reports and qualitative data indicating high levels of callers' satisfaction with services and high numbers of people using such services, including individuals in suicidal crises, are not sufficient to prove their impact on the actual prevalence of non-fatal and fatal suicidal behavior (Mishara \& Daigle, 2001). The recent development of online crisis intervention services, including specialized Websites and befriending via e-mail, seems to face identical difficulties in data collection and analysis.

In addition, globalization of the Internet raises important questions concerning the cultural appropriateness of Web-based mental health and suicide prevention interventions (Howlett \& Langdon, 2004; Mishara \& Daigle, 2001). Again, no published research is available in this area.

Future studies should evaluate the effectiveness of interventions involving both telecommunication technologies and traditional approaches to suicide 
prevention, e.g., traditional face-to-face psychotherapy supplemented with participation in an online support group as suggested by Prasad and Owens (2001).

The continuing development and use of telecommunication equipment and technologies requires more research concerning cost-effectiveness and sustainability of such programs. Available data indicates that telephone-based interventions and suicide risk assessment via videoconferencing do not overburden health providers and are feasible to run (De Leo et al., 2002; Evans et al., 2000; Jong, 2004). However, concerns have been raised with regard to resource implications for introduction of real time chat befriending (Howlett \& Langdon, 2004), and helpers' burnout and system capacity overload in Web-based crisis intervention services (Barak, 2007).

Another important question concerning the use and effectiveness of suicide prevention initiatives based upon telecommunication technologies relates to the theoretical basis and mechanisms of such interventions. Three explanations concerning the reported effectiveness of such initiatives have been proposed: interpersonal connectedness (Carter, Clover, Whyte, Dawson, \& D'Este, 2005; De Leo et al., 2002; Miller \& Gergen, 1998; Motto \& Bostrom, 2001), alternative problem solving (Mishara \& Daigle, 2001), and referral to appropriate services (Jones, 2002). Further research could help to better understand the dynamics of online and offline communications and crisis interventions, and needs of people at risk of suicide in order to design and implement effective telecommunication-based strategies. Table 2 summarizes potential future developments in the use of telecommunication technologies in suicide prevention and relevant areas of research.

\section{CONCLUSIONS}

Although a wide variety of technologies have been used to date in suicide prevention, no clear evidence is available in confirming their usefulness. However, the continuing development of telecommunication technologies opens new venues in suicidology. For example, studies using SMS technology to increase treatment compliance in primary care yielded encouraging results and possibly could be replicated in follow-up interventions for patients with a history of suicidal behavior.

Telecommunication-based approaches to suicide prevention seem quite promising and further research could deepen our knowledge concerning which types of interventions using which media of communication are effective in particular populations at risk of suicidal behavior and its repetition. Future studies could determine whether it is possible to prevent suicide and deliver effective treatment exclusively by phone or via the Internet, or if the use of these communication technologies is limited to supplementing the more traditional face-to-face interventions. 
Table 2. Potential Future Developments in the Use of Telecommunication Technologies in Prevention of Suicidal Behaviors and Suggested Further Research Areas

\begin{tabular}{|c|c|}
\hline Future developments & Future research \\
\hline \multirow{2}{*}{$\begin{array}{l}\text { - Further development of telecom- } \\
\text { munication-based crisis interven- } \\
\text { tion and psychotherapy for } \\
\text { individuals at risk of suicide } \\
\text { (including development of a } \\
\text { wide variety of interventions } \\
\text { tailored to suit individuals at } \\
\text { different levels of suicide risk) }\end{array}$} & $\begin{array}{l}\text { - Increased numbers of effectiveness and } \\
\text { efficacy studies for crisis intervention, } \\
\text { prevention, and postvention programs } \\
\text { using telecommunication technology } \\
\text { (including randomized controlled trials) }\end{array}$ \\
\hline & $\begin{array}{l}\text { - Research evaluating the effectiveness } \\
\text { of telecommunication-based suicide } \\
\text { prevention programs in a wide variety }\end{array}$ \\
\hline \multirow{2}{*}{$\begin{array}{l}\text { - Expanding use of new tech- } \\
\text { nologies in a wide range of } \\
\text { suicide prevention initiatives } \\
\text { (e.g., SMS in follow-up interven- } \\
\text { tion programs to increase } \\
\text { treatment compliance and/or } \\
\text { interpersonal connectedness) }\end{array}$} & $\begin{array}{l}\text { of demographic (e.g., age, gender, } \\
\text { culture) and clinical subpopulations } \\
\text { (e.g., different levels of suicide risk) }\end{array}$ \\
\hline & $\begin{array}{l}\text { - Research evaluating the effectiveness of } \\
\text { online based suicide prevention educa- } \\
\text { tion and training programs for mental } \\
\text { health professionals and the general }\end{array}$ \\
\hline \multirow[b]{2}{*}{$\begin{array}{l}\text {-Use of multi-technology appli- } \\
\text { cations (e.g., crisis intervention } \\
\text { using both telephone and } \\
\text { online-based resources, } \\
\text { including e-mails and chat } \\
\text { rooms) }\end{array}$} & population \\
\hline & $\begin{array}{l}\text { - Studies of phenomena related to online- } \\
\text { based communication (including virtual } \\
\text { Werther effect, dynamics of online } \\
\text { suicide pacts and Web-based self-help } \\
\text { groups) }\end{array}$ \\
\hline $\begin{array}{l}\text { Use of telecommunication tech- } \\
\text { nologies intertwined with } \\
\text { face-to-face interventions (e.g., } \\
\text { traditional face-to-face psycho- } \\
\text { therapy mixed with e-mail-based } \\
\text { and/or telephone interventions) }\end{array}$ & $\begin{array}{l}\text { - Studies of mechanisms of effective } \\
\text { suicide prevention programs utilizing } \\
\text { telecommunication technologies } \\
\text { (e.g., the role of interpersonal } \\
\text { connectedness and/or support based } \\
\text { upon referral and information) }\end{array}$ \\
\hline \multirow[t]{3}{*}{$\begin{array}{l}\text { - Further development of } \\
\text { Web-based support and referral } \\
\text { services for suicide survivors }\end{array}$} & $\begin{array}{l}\text { - Further development of research } \\
\text { methodology tailored to suit the specific } \\
\text { context of telecommunication-based } \\
\text { interventions (including anonymity of } \\
\text { users and confidentiality of services) }\end{array}$ \\
\hline & $\begin{array}{l}\text { - Studies evaluating the cost-effectiveness } \\
\text { and sustainability of telecommunication- } \\
\text { based interventions }\end{array}$ \\
\hline & $\begin{array}{l}\text { - Further consideration and development } \\
\text { of medico-legal guidelines for } \\
\text { telecommunication-based suicide } \\
\text { prevention initiatives and programs }\end{array}$ \\
\hline
\end{tabular}




\section{REFERENCES}

Adamek, M. E., \& Kaplan, M.. (1996). Managing elder suicide: A profile of American and Canadian crisis prevention centres. Suicide and Life-Threatening Behaviour, 26, $122-131$.

Bale, C. (2001). Befriending in cyberspace: Challenges and opportunities. Crisis, 22, $10-11$.

Ball, D. (2000). A virtual cry for help? British Journal of Psychiatry, 177, 568.

Barak, A. (2007). Emotional support and suicide prevention through the Internet: A field project report. Computers in Human Behaviour, 23, 971-984.

Barak, A., \& Miron, O. (2005). Writing characteristics of suicidal people on the Internet: A psychological investigation of emerging social environments. Suicide and Life-Threatening Behaviour, 35, 507-524.

Barber, J. G., Blackman, E. K., Talbot, C., \& Saebel, J. (2004). The themes expressed in suicide calls to a telephone help line. Social Psychiatry and Psychiatric Epidemiology, 39, 121-125.

Baume, P., Cantor, C. H., \& Rolfe, A. (1997). Cybersuicide: The role of interactive suicide notes on the Internet. Crisis, 18, 73-79.

Beatson, S., Hosty, G. S., \& Smith, S. (2000). Suicide and the Internet. Psychiatric Bulletin, 24, 434 .

Becker, K., Mayer, M., Nagenborg, M., El-Faddagh, M., \& Schmidt, M. H. (2004). Parasuicide online: Can suicide Websites trigger suicidal behaviour in predisposed adolescents. Nordic Journal of Psychiatry, 58, 111-114.

Becker, K., \& Schmidt, M. H. (2004). Internet chat rooms and suicide. Journal of the American Academy of Child and Adolescent Psychiatry, 43, 246-247.

Birnbaum, L., \& Birnbaum, A. (2004). In search of inner wisdom: Guided mindfulness meditation in context of suicide. Scientific World Journal, 4, 216-227.

Borzekowski, D. L. G., \& Ricket, V. I. (2001). Adolescent cybersurfing for health information. Archives of Paediatrics and Adolescent Medicine, 155, 813-817.

Burns, J. M., \& Patton, G. C. (2000). Preventive interventions for youth suicide: A risk factor-based approach. Australian and New Zealand Journal of Psychiatry, 34, 388-407.

Carter, G. L., Clover, K., Whyte, I. M., Dawson, A. H., \& D’Este, C. (2005). Postcards form the Edge project: Randomised controlled trial of an intervention using postcards to reduce repetition of hospital treated deliberate self-poisoning. British Medical Journal, 331, 805-809.

Cedereke, M., Monti, K., \& Ojehagen, A. (2002). Telephone contact with patients in the year after a suicide attempt: Does it affect treatment attendance and outcome? A randomised controlled study. European Psychiatry, 17, 82-91.

Commonwealth Department of Health and Aged Care. (2000). Building partnerships, LIFE: A framework for prevention of suicide and self-harm in Australia. Canberra: Commonwealth Department of Health and Aged Care.

De Leo, D., Carollo, G., \& Dello Buono, M. (1995). Lower suicide rates associated with a Tele-Help/Tele-Check service for the elderly at home. American Journal of Psychiatry, 152, 632-634.

De Leo, D., Dello Buono, M., \& Dwyer, J. (2002). Suicide among the elderly: The long term impact of a telephone support and assessment intervention in northern Italy. British Journal of Psychiatry, 181, 226-229. 
De Leo, D., \& Heller, T. (in press). Intensive case management in suicide attempters following discharge from inpatient psychiatric care. Community Mental Health Journal.

Dew, M. A., Bromet, E. J., Brent, D., \& Greenhouse, J. B. (1987). A quantitative literature review of the effectiveness of suicide prevention centers. Journal of Consulting and Clinical Psychology, 55, 239-244.

Downer, S. R., Meara, J. G., \& Da Costa, A. C. (2005). Use of SMS messaging to improve outpatient attendance. Medical Journal of Australia, 183, 366-368.

Ellen, E. F. (2002). Identifying and treating suicidal college students. Psychiatric Times, $19,8$.

Evans, M. O., Morgan, G., \& Hayward, A. (2000). Crisis telephone consultation for deliberate self-harm patients: How the study groups used the telephone and usual health-care services. Journal of Mental Health, 9, 155-164.

Evans, M. O., Morgan, H. G., Hayward, A., \& Gunnell, D. J. (1999). Crisis telephone consultation for deliberate self-harm patients: Effects on repetition. British Journal of Psychiatry, 175, 23-27.

Fekete, S., \& Osvath, P. (2001). The Internet: Data on suicide, depression and anxiety. In O. T. Grad (Ed.), Suicide risk and protective factors in the new millennium (pp. 147-151). Ljubljana: Cankarjev dom.

Gallagher, K. E., Smith, D. M., \& Mellen, P. F. (2003). Suicidal asphyxiation by using pure helium gas: Case report, review, and discussion of the influence of the Internet. American Journal of Forensic Medicine and Pathology, 24, 361-363.

Goss, S., \& Anthony, K. (2004). Ethical and practical dimensions of online writing cures. In G. Bolton, S. Howlett, C. Lago, \& J. K. Wright (Eds.), Writing cures: An introductory handbook of writing in counselling and therapy (pp. 170-178). Hove/New York: Brunner-Routledge.

Gould, M. S., \& Kramer, R. A. (2001). Youth suicide prevention. Suicide and LifeThreatening Behaviour, 31, 6-31.

Gould, M. S., Munfakh, J. L. H., Lubell, K., Lubell, K., Kleinman, M., \& Parker, S. (2002). Seeking help from the Internet during adolescence. Journal of the American Academy of Child and Adolescent Psychiatry, 41, 1182-1189.

Griffiths, L. (2004). Electronic text-based communication-Assumptions and illusions created by the transference phenomena. In G. Bolton, S. Howlett, C. Lago, \& J. K. Wright (Eds.), Writing cures: An introductory handbook of writing in counselling and psychotherapy (pp. 151-159). Hove/New York: Brunner-Routledge.

Hatcher, S., \& Owens, D. (2005). Do get in touch. Postcards from the hospital may lead to fewer episodes of self-harm. British Medical Journal, 331, 788-789.

Hawgood, J., Irving, R., Guo, E., Gilmour, M., \& De Leo, D. (2006, March). Online education: The electronic suicide prevention skills training. Paper presented at the Queensland Suicide and Self-Harm Prevention Conference, Brisbane, Australia.

Howlett, S., \& Langdon, R. (2004). Messages to Jo: The Samaritans' experience of email befriending. In G. Bolton, S. Howlett, C. Lago, \& J. K. Wright (Eds.), Writing cures: An introductory handbook of writing in counselling and psychotherapy (pp. 160-167). Hove/New York: Brunner-Routledge.

Janson, M. P., Alessandrini, E. S., Strunjas, S. S., Sahab, H., El-Malakh, R., \& Lippmann, S. B. (2001). Internet-observed suicide attempts. Journal of Clinical Psychiatry, 62, 478 . 
Joinson, A. (1998). Causes and implications of disinhibited behaviour on the Internet. In J. Gackenbach (Ed.), Psychology and the Internet: Intrapersonal, interpersonal, and transpersonal implications (pp. 43-60). San Diego: Academic Press.

Jones, B. N. (2002). Suicide among the elderly: The promise of telecommunications. British Journal of Psychiatry, 181, 191-192.

Jong, M. (2004). Managing suicides via videoconferencing in a remote northern community in Canada. International Journal of Circumpolar Health, 63, 422-428.

King, E., \& Frost, N. (2005). The New Forest Suicide Prevention Initiative. Crisis, 26, 25-33.

King, R., Nurcombe, B., Bickman, L., Hides, L., \& Reid, W. (2004). Telephone counselling for adolescent suicide prevention: Changes in suicidality and mental state from beginning to end of a counselling session. Suicide and Life-Threatening Behaviour, 33, 400-411.

Koocher, G. P., \& Morray, E. (2000). Regulation of telepsychology: A survey of state attorneys general. Professional Psychology: Research and Practice, 31, 503-508.

Kraus, R. (2004). Ethical and legal considerations for providers of mental health services online. In R. Kraus, J. S. Zack, G. \& Stricker (Eds.), Online counselling: A handbook for mental health professionals (pp. 123-144). Amsterdam: Elsevier Academic Press.

Lee, D. T. S., Chan, K. P. M., \& Yip, P. S. F. (2005). Charcoal burning is also popular for suicide pacts made on the Internet. British Medical Journal, 330, 602.

Lester, D. (1997). The effectiveness of suicide prevention centres: A review. Suicide and Life-Threatening Behaviour, 27, 304-311.

Lester, D. (2005). Suicide by jumping from bridges. Perceptual and Motor Skills, 100,628 .

Maheu, M. M., Pulier, M. L., Wilhelm, F. H., McMenamin, J. P., \& Brown-Connolly, N. E. (2005). The mental health professional and the new technologies: A handbook for practice today. Mahwah, NJ: Lawrence Erlbaum Associates, Publishers.

Mehlum, L. (2000). The Internet, suicide, and suicide prevention. Crisis, 21, 186-188.

Mehlum, L. (2001). The Internet and suicide prevention. In O. T. Grad (Ed.), Suicide risk and protective factors in the new millennium (pp. 223-227). Ljubljana: Cankarjev dom.

Miller, H. L., Coombs, D. W., Leeper, J. D., \& Barton, S. N. (1984). An analysis of the effects of suicide prevention facilities on suicide rates in the United States. American Journal of Public Health, 74, 340-343.

Miller, J. K., \& Gergen, K. J. (1998). Life on line: The therapeutic potentials of computer-mediated conversation. Journal of Marital and Family Therapy, 24, 189-202.

Minister of Justice and Custom. (2005). Suicide prevention in Australia strengthened by new laws. Retrieved June 2, 2006 from http://www.ag.gov.au/agd/WWW/justiceministerHome.nsf/D2801B61EABE80A2C A256809001328BA/6948DA9800D5F664CA25702A0013D3CC

Mishara, B. (2005). A Silent Monitoring Study of telephone help provided over the Hopeline Network and its short-term effects. In Suicide prevention hotlines in Georgia: July 2004-June 2005 FY Annual Summary. Atlanta, GA: Behavioural Health Link. Retrieved June 2, 2006 from http://mhddad.dhr.georgia.gov/DHR-MHDDAD/DHR-MHDDAD_CommonFiles/A S\%20Suicide\%20Hotlines\%20GA\%2005.pdf 
Mishara, B., \& Daigle, M. (2001). Helplines and crisis intervention services: Challenges for the future. In D. Lester (Ed.), Suicide prevention: Resources for the millennium (pp. 153-169). Philadelphia: Brunner-Routledge.

Mishara, B., Houle, J., \& Lavoie, B. (2005). Comparison of the effects of four suicide prevention programs for family and friends of high-risk suicidal men who do not seek help themselves. Suicide and Life-Threatening Behaviour, 35, 329-342.

Morgan, H. G., Jones, E. M., \& Owen, J. H. (1993). Secondary prevention of non-fatal deliberate self-harm. The green card study. British Journal of Psychiatry, 163, 111-112.

Motto, J. A. (1976). Suicide prevention for high-risk persons who refuse treatment. Suicide and Life-Threatening Behaviour, 6, 223-230.

Motto, J. A., \& Bostrom, A. G. (2001). A randomized controlled trial of postcrisis suicide prevention. Psychiatric Services, 52, 828-833.

Murphy, L. J., \& Mitchell, D. L. (1998). When writing helps to heal: Email as therapy. British Journal of Guidance and Counselling, 26, 21-33.

New Zealand Ministry of Health. (1998). In our hands. New Zealand Youth Suicide Prevention Strategy. Wellington: Ministry of Youth Affairs.

Nicholas, J., Oliver, K., Lee, K., \& O’Brien, M. (2004). Help-seeking behaviour and the Internet: An investigation among Australian adolescents. Australian e-Journal for the Advancement of Mental Health, 3, 1-8.

Penn, D., Simpson, L., Edie G., Leggett, S., Wood, L., Hawgood, J., Krysinska, K., Yellowlees, P., \& De Leo, D. (2005). Development of ACROSSnet: An online support system for rural and remote community suicide prevention workers in Queensland, Australia. Health Informatics Journal, 11, 275-293.

Prasad, V., \& Owens, D. (2001). Using the Internet as a source of self-help for people who self-harm. Psychiatric Bulletin, 25, 222-225.

Prior, T. I. (2004). Suicide methods from the Internet. American Journal of Psychiatry, 161, 1500-1501.

Quinnett, P. (2004). Global suicide-prevention education for healthcare professionals. Retrieved June 2, 2006 from http://www.globaled.com/articles/PaulQuinnett2004.pdf

Rajagopal, S. (2004). Suicide pacts and the Internet. British Medical Journal, 329, 1298-1299.

Rhee, W. K., Merbaum, M., Strube, M. J., \& Self, S. M. (2005). Efficacy of a brief telephone psychotherapy with callers to a suicide hotline. Suicide and LifeThreatening Behaviour, 35, 317-328.

Sher, L. (2000). The Internet, suicide, and human mental functions. Canadian Journal of Psychiatry, 45, 297.

Sisask, M., Varnik, A., \& Wasserman, D. (2005). Internet comments on media reporting of two adolescents' collective suicide attempt. Archives of Suicide Research, 9, 87-98.

Stone, D. M., Barber, C. W., \& Potter, L. (2005). Public health training online: The National Centre for Suicide Prevention Training. American Journal of Preventive Medicine, 29, 5S2, 247-251.

Stoney, G. (1998). Suicide prevention on the Internet. In R. J. Kosky, H. S. Eshkevari, R. D. Goldney, \& R. Hassan (Eds.), Suicide prevention: The global context (pp. 237-244). New York: Plenum Press.

Thompson, S. (2001). Suicide and the Internet. Psychiatric Bulletin, 25, 400. 
U.S. Department of Health and Human Services. (2001). National strategy for suicide prevention: Goals and objectives for action. Rockville, MD: U.S. Department of Health and Human Services.

Varah, C. (2001). The Samaritans: Befriending the suicidal. In E. S. Shneidman (Ed.), Comprehending suicide: Landmarks in 20th-century suicidology (pp. 167-177). Washington, DC: American Psychological Association.

Wilson, G., \& Lester, D. (1998). Suicide prevention by e-mail. Crisis Intervention, 4, 81-87.

Wright, J. K. (2004). Developing online, text-based counselling in the workplace. In G. Bolton, S. Howlett, C. Lago, \& J. K. Wright (Eds.), Writing cures: An introductory handbook of writing in counselling and therapy (pp. 142-150). Hove/New York: Brunner-Routledge.

Ybarra, M. L., \& Suman, M. (2006). Help seeking behaviour and the Internet: A national survey. International Journal of Medical Informatics, 75, 29-41.

Direct reprint requests to:

Diego De Leo

Director

Australian Institute for Suicide Research and Prevention

WHO Collaborating Centre for Research and Training in Suicide Prevention

Griffith University

Mt. Gravatt Campus

Brisbane, Qld 4111 Australia

e-mail: d.deleo@griffith.edu.au 